\title{
Chemoembolization Plus Microwave Ablation vs Chemoembolization Alone in Unresectable Hepatocellular Carcinoma Beyond the Milan Criteria: A Propensity Scoring Matching Study
}

\author{
Hui-Zhou Li (iD) \\ Jie Tan (D) \\ Tian Tang ${ }^{2}$ \\ Tian-Zhi $\mathrm{An}^{3}$ \\ Jun-Xiang $\mathrm{Li}^{4}$ \\ Yu-Dong Xiao iD \\ 'Department of Radiology, The Second \\ Xiangya Hospital of Central South \\ University, Changsha, 4I00II, People's \\ Republic of China; ${ }^{2}$ Department of \\ Interventional Radiology, The Affiliated \\ Cancer Hospital of Xiangya School of \\ Medicine, Central South University, \\ Changsha, 410013, People's Republic of \\ China; ${ }^{3}$ Department of Interventional \\ Radiology, The Affiliated Hospital of \\ Guizhou Medical University, Guiyang, \\ 550002, People's Republic of China; \\ ${ }^{4}$ Department of Interventional Radiology, \\ Guizhou Medical University Affiliated \\ Cancer Hospital, Guiyang, 550004, \\ People's Republic of China
}

Correspondence: Yu-Dong Xiao Department of Radiology, The Second Xiangya Hospital of Central South University, No. 139 Middle Renmin Road, Changsha, 4I00II, People's Republic of China

Tel +86 I3637403027

Fax +86 731-85292116

Email xiaoyudong222@csu.edu.cn
Purpose: Transarterial chemoembolization (TACE) is recommended in patients with unresectable HCC beyond the Milan criteria (MC). However, the long-term efficacy of TACE remains unsatisfactory. Percutaneous microwave ablation (MWA) is a curative therapy for early-stage HCC that provides better local tumor control than TACE; however, MWA is limited for large or multifocal lesions. We aimed to compare treatment efficacy and downstaging rate following combined TACE-MWA and TACE alone in patients with unresectable HCC beyond the MC.

Patients and Methods: Patients with unresectable HCC beyond the MC who underwent either TACE-MWA $(n=91)$ or TACE alone $(n=140)$ at four medical institutions were included. Potential influencing factors on overall survival (OS) and progression-free survival (PFS) were included in the Cox regression analysis. Propensity-score matching of patients treated with TACE-MWA and TACE alone was performed. Differences in OS and PFS were compared with the Log rank test. Patients who met the University of California, San Francisco criteria were eligible for assessment of the probability of downstaging within the MC. Downstaging rate was compared between the two groups.

Results: In multivariate analysis, treatment with TACE alone was an independent predictor of poor PFS $(\mathrm{P}=0.011)$ and $\mathrm{OS}(\mathrm{P}<0.001)$. Both PFS $(\mathrm{P}=0.043)$ and $\mathrm{OS}(\mathrm{P}=0.002)$ were significantly higher in patients treated with TACE-MWA than those treated with TACE alone. The downstaging rate was higher in patients treated with TACE-MWA than those treated with TACE alone ( $\mathrm{P}=0.039)$.

Conclusion: Compared with TACE alone, TACE-MWA may offer a survival benefit in terms of OS and PFS in HCC patients beyond the MC. Additionally, TACE-MWA may provide higher probability of downstaging within the MC than TACE alone, thereby increasing the possibility of liver transplantation.

Keywords: microwave ablation, transarterial chemoembolization, survival, propensity score-matching, Milan criteria

\section{Introduction}

Hepatocellular carcinoma (HCC) is a major problem worldwide, with high morbidity and mortality. ${ }^{1,2}$ According to the Barcelona Clinic Liver Cancer (BCLC) system, ablation is recommended as the first-line treatment for $\mathrm{HCC}$ patients with BCLC-0 or as an alternative treatment option for HCC patients with BCLC-A. In contrast, transarterial chemoembolization (TACE) is recommended as the primary 
treatment for HCC patients with BCLC-B. ${ }^{1,3}$ Aside from ablation and TACE, transarterial radioembolization (TARE) is a liver-directed therapy that is widely used in clinical practice. ${ }^{4-6}$ Although TARE is not recommended in the latest version of the BCLC system, it may provide survival benefit in select patients. ${ }^{7,8}$ Since 1996, the Milan criteria (MC) has been widely used to select patients who are candidates for liver transplantation. In contrast, transarterial chemoembolization (TACE) is recommended for patients with unresectable HCC beyond MC..$^{9-11}$ However, the long-term efficacy of TACE is still not satisfactory, mainly due to incomplete tumor necrosis and liver function damage induced by the procedure. ${ }^{12,13}$ Percutaneous microwave ablation (MWA) has long been accepted as a curative therapy for early-stage HCC and can provide better local tumor control than TACE. ${ }^{14,15}$ However, the use of ablation in large or multifocal lesions is limited. ${ }^{16,17}$ The combination of TACE and thermal ablation may increase the treatment efficacy for HCC lesions in selected patients. ${ }^{16-18}$ However, the treatment efficacy of TACE plus MWA compared with TACE alone for patients with unresectable $\mathrm{HCC}$ beyond $\mathrm{MC}$ has not yet been elucidated. In addition, the probability of downstaging within the MC following the two treatment modalities has not been compared. Therefore, the purpose of this study was to compare the therapeutic outcomes of TACE in combination with MWA with that of TACE alone for patients with unresectable $\mathrm{HCC}$ beyond $\mathrm{MC}$ and compare the downstaging rate between the two treatment modalities.

\section{Materials and Methods}

\section{Patients}

This retrospective study was approved by the institutional review board of the Second Xiangya Hospital and was performed in accordance with the Declaration of Helsinki. Written informed consent for publication from all patients was waived by the institutional review boards due to the retrospective nature of the present study and all patients' data for analysis were anonymized.

A total of 1028 patients with unresectable HCC who underwent TACE plus MWA or TACE alone between September 2014 and September 2020 at four institutions were included in this retrospective study. The indication for TACE-MWA or TACE alone was assessed by a tumor board consisting of surgeons, hepatologists, oncologists, radiologists, and interventional radiologists. Patients meeting the following criteria were initially performed with TACE: (a) preserved

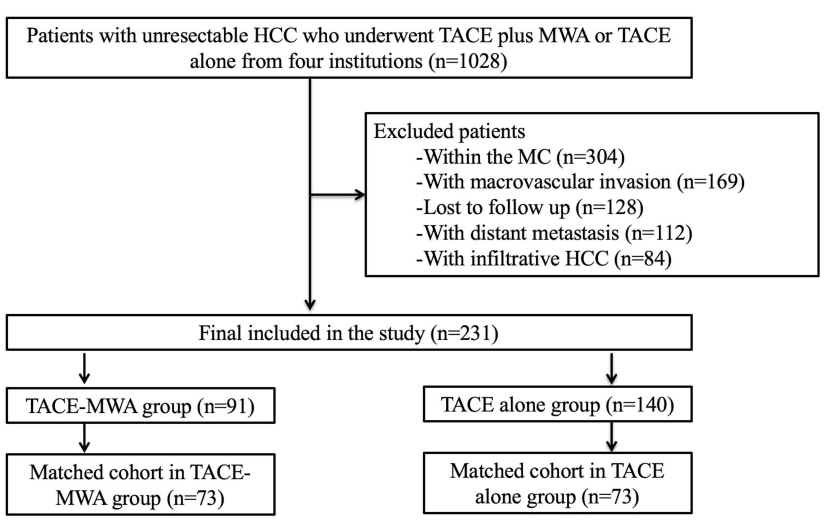

Figure I Flowchart of the study population.

liver function (Child-Pugh A or B); (b) Eastern Cooperative Oncology Group performance status 0; and (c) at least one target lesion for measurement. Patients meeting the following criteria were further performed with MWA after initial TACE: (a) the presence of a single $\mathrm{HCC}$ tumor $\leq 8 \mathrm{~cm}$ in diameter, or multi-nodular HCC tumors $(\mathrm{n} \leq 5)$ small than $5 \mathrm{~cm}$ in diameter before TACE and (b) the presence of viable residual tumor on follow-up imaging. The exclusion criteria were: (a) classification within the $\mathrm{MC}(\mathrm{n}=304)$; (b) macrovascular invasion $(\mathrm{n}=169)$; (c) loss to follow-up ( $\mathrm{n}=128)$; (d) distant metastasis $(\mathrm{n}=112)$; (e) infiltrative HCC ( $\mathrm{n}=84)$. Ultimately, 231 patients were included in the present study and divided into a TACEMWA ( $\mathrm{n}=91$ ) group and a TACE alone $(\mathrm{n}=140)$ group. Among the 231 patients, 71 patients were from institution $\mathrm{A}, 74$ patients were from institution $\mathrm{B}, 45$ patients were from institution $\mathrm{C}$, and 41 patients were from institution $\mathrm{D}$. The flowchart of the study population is shown in Figure 1.

\section{TACE Procedure}

TACE was performed by eight board-certified senior interventional radiologists with an average experience of 13 years in liver interventions. The femoral artery was routinely catheterized. Selective hepatic arteriography was performed to demonstrate the blood supply of the tumor, following which a 2.2-F coaxial microcatheter (Carnelian; Tokai Medical Products, Aichi, Japan) was placed in the tumor feeders. Chemoembolization was performed in a superselective manner by slowly injecting the oil-epirubicin emulsion through the microcatheter and subsequently administering the Gelfoam slurry to embolize the proximal tumor feeders. The oilepirubicin emulsion was created by mixing up to $15 \mathrm{~mL}$ of iodized oil (Lipiodol; Guerbet Asia Pacific Ltd., Hong Kong, China) with distilled water containing 50-120 mg of dissolved epirubicin (3:1 ratio). 


\section{MWA Procedure}

Within a month of TACE, dynamic contrast-enhanced CT or MR imaging was applied to identify the target lesions to be treated with MWA. MWA was performed using a single water-cooled microwave system (KY-2000; Kangyou Medical Instrument Co., Ltd., Changzhou, China) by four board-certified senior interventional radiologists with an average experience of 11 years in liver interventions. The $14-G$ antenna was percutaneously inserted into the tumor under CT guidance. A single antenna was used for tumors less than $3.0 \mathrm{~cm}$ in diameter, while for tumors larger than $3.0 \mathrm{~cm}$, an overlapping ablation technique was used as preprocedurally planned. For multifocal lesions, a maximum of three lesions were treated in a single session, and the remaining lesions were treated approximately one week after the first MWA session. The microwave power was set at $60-80$ $\mathrm{W}$, and the procedure lasted for 5-25 minutes. Intraprocedural contrast-enhanced CT imaging was performed to determine the ablative safety margin of the tumor. The technical success of ablation was defined as complete ablation of the tumor with a safety margin of at least $0.5 \mathrm{~cm}$ in CT images.

\section{Follow-Up}

Follow-up imaging was performed within 3 months after the first treatment and then at approximately 2-month intervals. The primary outcome was progression-free survival (PFS), which was defined as the time interval between the first TACE session and death, tumor progression, or last followup (April 30, 2021). The secondary outcome was overall survival (OS), which was defined as the time interval between the first TACE session and death or last follow-up (April 30, 2021). Tumor progression was defined as progression of the target lesion or nontarget lesion, or occurrence of a new lesion according to the modified Response Evaluation Criteria in Solid Tumors (mRECIST). If tumor progression occurred, the choice of treatment modality for progressive $\mathrm{HCC}$ was dependent on the site of the tumor, liver function, and the general condition of the patient.

\section{Data Collection}

The baseline characteristics of the patients were collected, including clinical data, laboratory data, and radiological data. The clinical data included sex (male/female), age, etiology of cirrhosis (none/HBV/HCV/alcohol/cryptogenic), and Child-Pugh class $(\mathrm{A} / \mathrm{B})$. The laboratory data included platelet count and albumin, total bilirubin, and alpha- fetoprotein levels (AFP; $\leq 400 />400 \mathrm{ng} / \mathrm{mL}$ ). The radiological data included tumor distribution (unilobar/bilobar), size of the largest tumor, and the number of tumors (single/ multiple).

\section{Downstaging Criteria}

Patients within the University of California, San Francisco (UCSF) criteria were considered to be suitable for assessment of downstaging within the MC. ${ }^{19}$ Patients who met any of the following were defined as fulfilling the UCSF criteria: (a) one lesion of 5-8 cm; (b) two to three lesions with at least one lesion of $3-5 \mathrm{~cm}$ and a total tumor diameter up to $8 \mathrm{~cm}$; or (c) four to five lesions with none greater than $3 \mathrm{~cm}$ and a total tumor diameter of up to $8 \mathrm{~cm}$. Successful downstaging was defined as a reduction in the number and size of viable tumors to meet the MC, with a minimum follow-up of 3 months.

\section{Statistical Analysis}

Numerical data are expressed as the mean with SD or median with interquartile range (IQR). Categorical data are described using numbers and percentages. To compare the differences in baseline demographic, clinical, and biochemical characteristics between the TACE-MWA group and TACE alone group, the Student's $t$-test or the Mann-Whitney $U$-test was used for continuous variables, and the $\chi^{2}$ test was used for categorical variables. The OS and PFS rates were analyzed with the Kaplan-Meier method, and the difference in OS or PFS was compared with the Log rank test. In patients with multiple tumors, the characteristics of the largest tumor were recorded for analysis. Eleven factors that may potentially influence OS and PFS were analyzed with a Cox proportional hazards regression model, and these were treatment modality (TACE-MWA/TACE alone), sex (male/female), age ( $\leq 55 /$ $>55$ years $)$, AFP level $(\leq 400 />400 \mathrm{ng} / \mathrm{mL})$, platelet count $\left(\leq 50 />50 \times 10^{9} / \mathrm{L}\right)$, number of tumors (single/multiple), size of the largest tumor $(\leq 50 />50 \mathrm{~mm}$ ), tumor distribution (unilobar/bilobar), etiology of cirrhosis (none/HBV/HCV/alcohol/cryptogenic), albumin ( $\leq 35 />35 \mathrm{~g} / \mathrm{L}$ ), and total bilirubin $(\leq 17.1 />17.1 \mu \mathrm{mol} / \mathrm{L})$. All variables in the univariate analyses were entered into the multivariate analysis to assess their significance as independent predictors. Hazard ratios and respective 95\% confidence intervals (CIs) were compared.

To minimize the effect of potential confounders on selection bias, logistic regression analysis was used to perform propensity-score matching (PSM) between the TACE-MWA group and the TACE alone group. Independent variables 
entered into the PSM model included sex (male/female), age ( $\leq 55 />55$ years), AFP level $(\leq 400 />400 \mathrm{ng} / \mathrm{mL})$, platelet count $\left(\leq 50 />50 \times 10^{9} / \mathrm{L}\right)$, number of tumors (single/multiple), size of the largest tumor $(\leq 50 />50 \mathrm{~mm})$, tumor distribution (unilobar/bilobar), etiology of cirrhosis (none/HBV/HCV/ alcohol/cryptogenic), albumin ( $\leq 35 />35 \mathrm{~g} / \mathrm{L})$, and total bilirubin $(\leq 17.1 />17.1 \mu \mathrm{mol} / \mathrm{L})$. Each treatment group was matched according to the generated PSM using a caliper width of 0.1 . The OS, PFS, and downstaging rates after PSM were compared between the two groups. Statistical analyses were performed using statistical software (SPSS version 20; International Business Machines Corporation, Armonk, NY, USA) or R software (version 4.0.2; http:// www.R-project.org). Statistical tests were two-sided, and $\mathrm{P}<0.05$ indicated a significant difference.

\section{Results}

\section{Baseline Characteristics of the Study}

\section{Population}

The entire study population included 205 males and 26 females with a mean age of $56.4 \pm 11.7$ years (range: 28 to 83 years). The diagnosis of HCC was based on the pathology $(n=37)$ or the 2018 version of the Liver Imaging Reporting and Data System (LI-RADS) criteria ( $\mathrm{n}=194)$. There were 214 patients with Child-Pugh A HCC and 17 patients with Child-Pugh B HCC. In the entire study population, 113 patients had early-stage HCC (BCLC-A), and 118 patients had intermediate-stage HCC (BCLC-B). The baseline patient characteristics among the four institutions are illustrated in Table 1.

Table I The Baseline Patient Characteristics Among Four Institutions

\begin{tabular}{|c|c|c|c|c|c|c|}
\hline Characteristics & $\begin{array}{l}\text { Overall } \\
(n=231)\end{array}$ & $\begin{array}{l}\text { Institution } \\
\text { A }(n=7 I)\end{array}$ & $\begin{array}{l}\text { Institution } \\
\text { B }(n=74)\end{array}$ & $\begin{array}{l}\text { Institution } \\
C(n=45)\end{array}$ & $\begin{array}{l}\text { Institution } \\
D(n=4 I)\end{array}$ & $\mathbf{P}$ \\
\hline Age (years) & $56.2 \pm 11.6$ & $58.8 \pm 11.5$ & $55.3 \pm 11.0$ & $54.0 \pm 11.0$ & $55.7 \pm \mid 4.8$ & 0.083 \\
\hline Sex $(\%)$ & & & & & & 0.024 \\
\hline Male & 205 (88.7\%) & $65(91.5 \%)$ & 59 (79.7\%) & $4 \mid(91.1 \%)$ & $40(97.6 \%)$ & \\
\hline Female & 26 (11.3\%) & $6(8.5 \%)$ & $15(20.3 \%)$ & $4(7.9 \%)$ & I (2.4\%) & \\
\hline Number of tumors (\%) & & & & & & $<0.001$ \\
\hline Single & $113(48.9 \%)$ & $36(50.7 \%)$ & $32(43.2 \%)$ & $26(57.8 \%)$ & $19(46.3 \%)$ & \\
\hline Multiple & $118(51.1 \%)$ & $35(49.3 \%)$ & $42(56.8 \%)$ & $19(42.2 \%)$ & $22(53.7 \%)$ & \\
\hline Albumin ( $g / L$, median with IQR) & $56.2 \pm 11.6$ & $36.5 \pm 4.6$ & $38.8 \pm 5.3$ & $39.7 \pm 4.3$ & $38.5 \pm 6.0$ & 0.169 \\
\hline Total bilirubin (umol/L, median with IQR) & $15.3(11.6)$ & $15.6(13.4)$ & $15.9(8.0)$ & $14.9(7.5)$ & I5.5 (I3.4) & 0.830 \\
\hline Platelet $\left(\times 10^{9}\right.$, median with IQR) & $155.0(103.0)$ & $143.0(107.0)$ & $155.0(108.75)$ & $176.0(106.5)$ & $140.0(120.0)$ & 0.051 \\
\hline Child-Pugh class (\%) & & & & & & 0.088 \\
\hline$A$ & 214 (92.6\%) & $66(93.0 \%)$ & 67 (90.5\%) & 45 (100\%) & $36(87.8 \%)$ & \\
\hline B & 17 (7.4\%) & $5(7.0 \%)$ & 7 (9.5\%) & 0 & 5 (I2.2\%) & \\
\hline Etiologies of cirrhosis (\%) & & & & & & 0.038 \\
\hline None & 27 (11.7\%) & $12(16.9 \%)$ & $5(6.8 \%)$ & I (2.2\%) & $9(22.0 \%)$ & \\
\hline $\mathrm{HBV}$ & I 88 (8I.4\%) & 54 (76.1\%) & 64 (86.5\%) & 41 (9I.1\%) & 29 (70.7\%) & \\
\hline $\mathrm{HCV}$ & 7 (3.0\%) & $3(4.2 \%)$ & $2(2.7 \%)$ & 0 & $2(4.9 \%)$ & \\
\hline Alcohol & $3(1.3 \%)$ & 0 & $2(2.7 \%)$ & I (2.2\%) & 0 & \\
\hline Cryptogenic & $6(2.6 \%)$ & $2(2.8 \%)$ & I (I.4\%) & $3(1.3 \%)$ & I (2.4\%) & \\
\hline Tumor distribution (\%) & & & & & & 0.584 \\
\hline Unilobar & $148(64.1 \%)$ & $43(60.6 \%)$ & $52(70.3 \%)$ & 27 (60.0\%) & $26(63.4 \%)$ & \\
\hline Bilobar & $83(35.9 \%)$ & 28 (39.4\%) & 22 (29.7\%) & $18(40.0 \%)$ & $15(36.6 \%)$ & \\
\hline AFP (\%) & & & & & & 0.134 \\
\hline$\leq 400 \mathrm{ng} / \mathrm{mL}$ & 142 (6I.5\%) & $40(56.3 \%)$ & 52 (70.3\%) & $23(51.1 \%)$ & 27 (65.9\%) & \\
\hline$>400 \mathrm{ng} / \mathrm{mL}$ & 89 (38.5\%) & 31 (43.7\%) & $22(29.7 \%)$ & 22 (48.9\%) & 14 (34.1\%) & \\
\hline The largest tumor size ( $\mathrm{mm}$, median with IQR) & $75.0(48.8)$ & $74.0(56.0)$ & $63.0(41.5)$ & $102.0(67.1)$ & $84.9(43.6)$ & $<0.001$ \\
\hline
\end{tabular}

Abbreviations: IQR, inter-quartile range; AFP, alpha fetoprotein. 

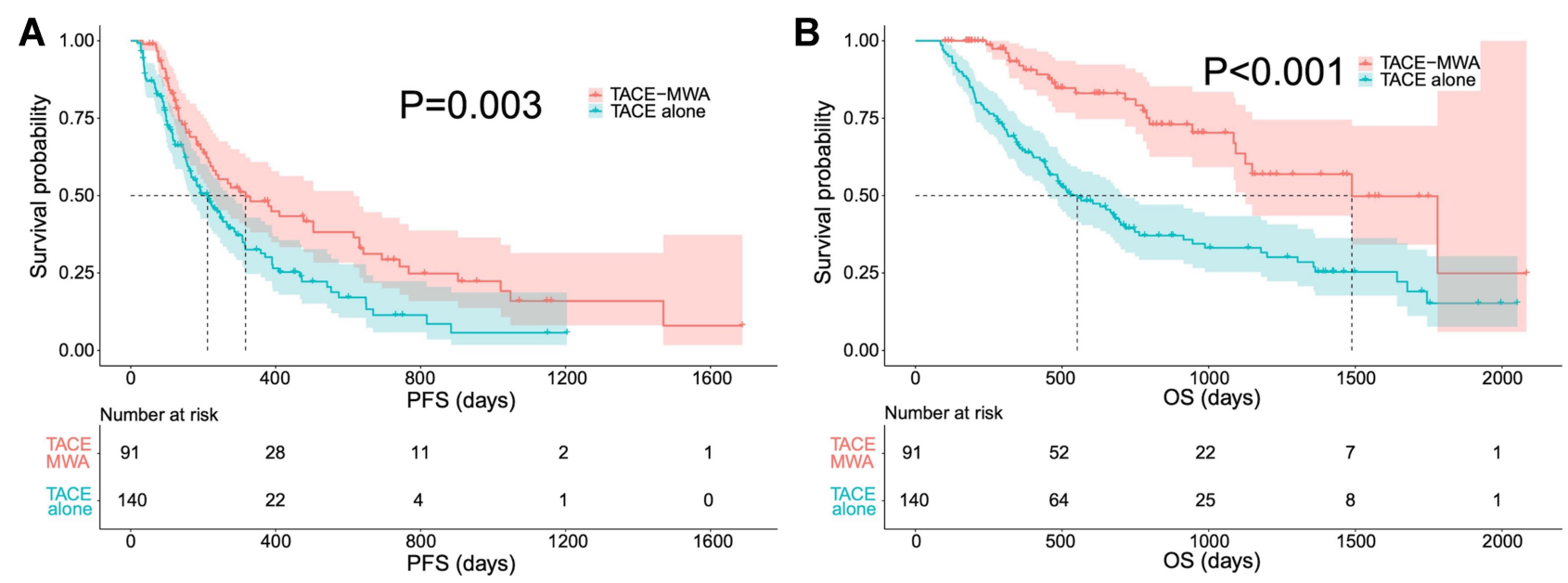

Figure 2 The comparison of PFS $(\mathbf{A})$ and OS $(\mathbf{B})$ before PSM. Both the PFS $(P=0.003)$ and the OS $(P<0.00 \mathrm{I})$ are significantly higher in patients treated with TACE-MWA than those of TACE alone.

\section{PFS Rates}

The median PFS was 317 days (95\% CI: 159-475) in the TACE-MWA group and 212 days (95\% CI: 155-268) in the TACE alone group. There was a significant difference in the PFS rate between the two groups (Figure 2A) $(\mathrm{P}=0.003)$. In the univariate analysis, poor PFS was associated with treatment with TACE alone $(\mathrm{P}=0.003)$, larger tumors $(\mathrm{P}=0.049)$, and multinodular HCCs $(\mathrm{P}=0.037)$. In the multivariate analyses, the three variables were independent predictors of poor PFS. Detailed information on the potential risk factors for poor PFS is listed in Table 2.

\section{OS Rates}

The mean follow-up period was 607 days in the TACE alone group and 724 days in the TACE-MWA group.
During the study period, 90 patients $(90 / 140,64.3 \%)$ in the TACE alone group and 25 patients $(25 / 91,27.5 \%)$ in the TACE-MWA group died. The median OS was 1488 days (95\% CI: 1119-1857) in the TACE-MWA group and 552 days (95\% CI: 416-688) in the TACE alone group. The 1 -, 2-, and 3-year survival rates were $92.0 \%, 81.1 \%$, and $63.6 \%$ in the TACE-MWA group, respectively, and $64.7 \%$, $39.4 \%$, and $33.1 \%$ in the TACE alone group, respectively. The OS in the TACE-MWA group was significantly longer compared to that in the TACE alone group (Figure 2B) $(\mathrm{P}<0.001)$. In the univariate analysis, poor OS was associated with treatment with TACE alone $(\mathrm{P}<0.001)$, higher AFP level $(>400 \mathrm{ng} / \mathrm{mL})(\mathrm{P}=0.039)$, bilobar tumor distribution $(\mathrm{P}=0.040)$, and larger tumors $(\mathrm{P}=0.016)$. In the multivariate analyses, larger tumors $(\mathrm{P}=0.029)$ and treatment

Table 2 Potential Risk Factors of Poor PFS for HCC Patients

\begin{tabular}{|c|c|c|c|c|c|}
\hline \multirow[t]{2}{*}{ Variables } & \multirow{2}{*}{$\begin{array}{l}\text { No. of } \\
\text { Cases }\end{array}$} & \multicolumn{2}{|l|}{ Univariate Analysis } & \multicolumn{2}{|l|}{ Multivariate Analysis } \\
\hline & & Hazard Ratio (95\% Cl) & $\mathbf{P}$ & Hazard Ratio $(95 \% \mathrm{Cl})$ & $\mathbf{P}$ \\
\hline Modalities (TACE-MWA/TACE alone) & $91 / 140$ & $1.662(1.189-2.322)$ & 0.003 & $1.614(1.116-2.332)$ & 0.011 \\
\hline Sex (male/female) & $205 / 26$ & $0.911(0.542-1.531)$ & 0.724 & $1.258(0.722-2.193)$ & 0.417 \\
\hline Age $(\leq 55 />55$ years $)$ & $115 / 116$ & $0.842(0.613-1.157)$ & 0.289 & $1.056(0.750-1.486)$ & 0.756 \\
\hline $\begin{array}{l}\text { Etiologies of cirrhosis (none/HBV/HCV/ Alcohol/ } \\
\text { Cryptogenic) }\end{array}$ & $27 / 188 / 7 / 3 / 6$ & $1.101(0.85 \mathrm{I}-1.425)$ & 0.465 & $1.283(0.968-1.701)$ & 0.083 \\
\hline Platelet count $\left(\leq 50 />50 \times 10^{9}\right)$ & $11 / 220$ & I.I $20(0.548-2.289)$ & 0.756 & $1.490(0.680-3.268)$ & 0.319 \\
\hline Albumin $(\leq 35 />35 \mathrm{~g} / \mathrm{L})$ & $62 / 169$ & $0.924(0.652-1.309)$ & 0.656 & $0.94 \mid(0.655-1.350)$ & 0.740 \\
\hline Total bilirubin $(\leq|7.| />17.1$ umol/L) & $143 / 88$ & $\mathrm{I} .043(0.754-\mathrm{I} .444)$ & 0.799 & $0.955(0.673-1.355)$ & 0.797 \\
\hline AFP level $(\leq 400 />400 \mathrm{ng} / \mathrm{mL})$ & $142 / 89$ & $\mathrm{I} .078(0.776-1.497)$ & 0.655 & $\mathrm{I} .053(0.747-1.485)$ & 0.767 \\
\hline Tumor distribution (unilobar/bilobar) & $|50 / 8|$ & 1.291 (0.930-I.792) & 0.127 & $1.066(0.74 \mid-1.534)$ & 0.730 \\
\hline Size of the largest tumor $(\leq 50 />50 \mathrm{~mm})$ & $49 / 182$ & $1.512(1.003-2.280)$ & 0.049 & $2.158(1.335-3.488)$ & 0.002 \\
\hline Number of tumors (single/multiple) & $113 / 118$ & $1.410(1.022-1.946)$ & 0.037 & $2.083(1.378-3.146)$ & $<0.001$ \\
\hline
\end{tabular}

Abbreviations: PFS, progression-free survival; HCC, hepatocellular carcinoma; TACE, transarterial chemoembolization; MWA, microwave ablation; AFP, Alpha fetoprotein. 
with TACE alone $(\mathrm{P}<0.001)$ were independent predictors of poor OS. Detailed information on the potential risk factors for poor OS is listed in Table 3.

\section{PSM Analysis}

Before PSM, there were no significant differences between the TACE-MWA group and the TACE alone group in terms of age $(\mathrm{P}=0.090)$, etiology of cirrhosis $(\mathrm{P}=0.483)$, Child-Pugh class $(\mathrm{P}=0.235)$, tumor distribution $(\mathrm{P}=0.299)$, platelet count $(\mathrm{P}=0.534)$, albumin $(\mathrm{P}=0.298)$, total bilirubin $(\mathrm{P}=0.196)$, or the number of tumors $(\mathrm{P}=0.224)$. However, there were significant differences in terms of $\operatorname{sex}(\mathrm{P}=0.004)$, AFP level $(\mathrm{P}=0.026)$, and size of the largest tumor $(\mathrm{P}<0.001)$ between the two groups. After PSM, a total of 146 patients were matched, including 73 patients in the TACE-MWA group and 73 patients in the TACE alone group. There were no differences in the baseline characteristics between the two groups after PSM. The detailed baseline characteristics of the patients before and after PSM are illustrated in Table 4.

\section{Comparison of PFS and OS Rates Between the TACE-MWA Group and TACE Alone Group After PSM}

After PSM, the median PFS was 380 days (95\% CI: 226728 ) in the TACE-MWA group and 247 days (95\% CI: 146-348) in the TACE alone group. There was a significant difference in the PFS rate between the two groups after PSM $(\mathrm{P}=0.043)$ (Figure $3 \mathrm{~A})$. The median OS was 1488 days (95\% CI: 1070-1906) in the TACE-MWA group and 700 days (95\% CI: 208-1192) in the TACE alone group. The 1-, 2-, and 3-year survival rates were $93.6 \%, 80.5 \%$, and $61.6 \%$ in the TACE-MWA group, respectively, and $72.4 \%, 48.9 \%$, and $41.9 \%$ in the TACE alone group, respectively. The OS in the TACE-MWA group was significantly higher than that in the TACE alone group $(\mathrm{P}=0.002)$ (Figure $3 \mathrm{~B})$.

\section{Comparison of the Downstaging Rate Between the TACE-MWA Group and TACE Alone Group After PSM}

After PSM, there were 48 patients in the TACE-MWA group and 26 patients in the TACE alone group within the UCSF criteria who were eligible for the assessment of downstaging probability. Among the 48 patients in the TACE-MWA group, 37 patients achieved a successful downstaging, with a downstaging rate of $77.1 \%$ (37/48). In the TACE alone group, 14 patients achieved successful downstaging, with a downstaging rate of $53.8 \%(14 / 26)$. The downstaging rate in the TACE-MWA group was significantly higher than that in the TACE alone group $(\mathrm{P}=0.039)$. Failure to downstage in the TACE-MWA group was mainly due to the occurrence of vascular invasion $(n=6)$, local tumor progression of the target lesions $(n=6)$, and extrahepatic metastasis $(n=4)$. Similarly, failure to downstage in the TACE alone group was mainly due to the occurrence of vascular invasion $(n=7)$, local tumor progression of the target lesions $(n=7)$, and extrahepatic metastasis $(n=3)$. Typical imaging of downstaging in the two groups is shown in Figures 4 and 5.

Table 3 Potential Risk Factors of Poor OS for HCC Patients

\begin{tabular}{|c|c|c|c|c|c|}
\hline \multirow[t]{2}{*}{ Variables } & \multirow{2}{*}{$\begin{array}{l}\text { No. of } \\
\text { Cases }\end{array}$} & \multicolumn{2}{|l|}{ Univariate Analysis } & \multicolumn{2}{|l|}{ Multivariate Analysis } \\
\hline & & Hazard Ratio (95\% Cl) & $\mathbf{P}$ & Hazard Ratio $(95 \% \mathrm{Cl})$ & $\mathbf{P}$ \\
\hline Modalities (TACE-MWA/TACE alone) & $91 / 140$ & $2.980(1.899-4.679)$ & $<0.001$ & $2.75 \mathrm{I}(1.678-4.510)$ & $<0.001$ \\
\hline Sex (male/female) & $205 / 26$ & $0.763(0.398-1.459)$ & 0.413 & $1.160(0.57 \mathrm{I}-2.357)$ & 0.681 \\
\hline Age $(\leq 55 />55$ years $)$ & $115 / 116$ & $0.808(0.559-1.167)$ & 0.255 & $1.095(0.73|-| .64 I)$ & 0.659 \\
\hline $\begin{array}{l}\text { Etiologies of cirrhosis (none/HBV/HCV/Alcohol/ } \\
\text { Cryptogenic) }\end{array}$ & $27 / 188 / 7 / 3 / 6$ & $0.963(0.7|8-1.29|)$ & 0.800 & $1.028(0.756-1.397)$ & 0.862 \\
\hline Platelet count $\left(\leq 50 />50 \times 10^{9}\right)$ & $1 \mathrm{I} / 220$ & I.I27 (0.459-2.766) & 0.794 & $1.081(0.409-2.856)$ & 0.875 \\
\hline Albumin $(\leq 35 />35 \mathrm{~g} / \mathrm{L})$ & $62 / 169$ & $0.972(0.650-1.455)$ & 0.891 & $0.912(0.604-1.376)$ & 0.660 \\
\hline Total bilirubin $(\leq|7.| />|7$.$| umol/L)$ & $143 / 88$ & $\mathrm{I} .059(0.728-|.54|)$ & 0.763 & I.I34 (0.764-I.682) & 0.532 \\
\hline AFP level $(\leq 400 />400 \mathrm{ng} / \mathrm{mL})$ & $142 / 89$ & $1.476(1.020-2.135)$ & 0.039 & $1.456(0.982-2.160)$ & 0.062 \\
\hline Tumor distribution (unilobar/bilobar) & $|50 / 8|$ & $1.476(1.018-2.139)$ & 0.040 & $\mathrm{I} .404(0.942-2.09 \mathrm{I})$ & 0.095 \\
\hline Size of the largest tumor $(\leq 50 />50 \mathrm{~mm})$ & $49 / 182$ & $1.888(1.127-3.162)$ & 0.016 & $1.984(1.073-3.666)$ & 0.029 \\
\hline Number of tumors (single/multiple) & $113 / 118$ & $1.190(0.823-1.719)$ & 0.356 & $1.412(0.906-2.203)$ & 0.128 \\
\hline
\end{tabular}

Abbreviations: OS, overall survival; HCC, hepatocellular carcinoma; TACE, transarterial chemoembolization; MWA, microwave ablation; AFP, Alpha fetoprotein. 
Table 4 Baseline Characteristics of Patients Before and After PSM

\begin{tabular}{|c|c|c|c|c|c|c|}
\hline \multirow[b]{2}{*}{ Characteristics } & \multicolumn{3}{|l|}{ Before PSM } & \multicolumn{3}{|l|}{ After PSM } \\
\hline & $\begin{array}{l}\text { TACE+MWA } \\
(n=91)\end{array}$ & $\begin{array}{l}\text { TACE Alone } \\
(n=\mid 40)\end{array}$ & $\mathbf{P}$ & $\begin{array}{l}\text { TACE-MWA } \\
(n=73)\end{array}$ & $\begin{array}{l}\text { TACE Alone } \\
(n=73)\end{array}$ & $\mathbf{P}$ \\
\hline Sex & & & 0.004 & & & 1.000 \\
\hline Male & 74 & $13 \mid$ & & 67 & 67 & \\
\hline Female & 17 & 9 & & 6 & 6 & \\
\hline Age & & & 0.090 & & & 0.098 \\
\hline$\leq 55$ years & 39 & 76 & & 31 & 41 & \\
\hline$>55$ years & 52 & 64 & & 42 & 32 & \\
\hline Etiologies of cirrhosis & & & 0.483 & & & 0.966 \\
\hline None & 8 & 19 & & 7 & 5 & \\
\hline HBV & 77 & 111 & & 62 & 63 & \\
\hline $\mathrm{HCV}$ & 3 & 4 & & 2 & 2 & \\
\hline Alcohol & 2 & 1 & & 1 & I & \\
\hline Cryptogenic & 1 & 5 & & 1 & 2 & \\
\hline Platelet count & & & 0.534 & & & 0.719 \\
\hline$\leq 50 \times 10^{9}$ & 3 & 8 & & 3 & 5 & \\
\hline$>50 \times 10^{9}$ & 88 & 132 & & 70 & 68 & \\
\hline Albumin & & & 0.298 & & & 0.715 \\
\hline$\leq 35 \mathrm{~g} / \mathrm{L}$ & 21 & 41 & & 20 & 22 & \\
\hline$>35 \mathrm{~g} / \mathrm{L}$ & 70 & 99 & & 53 & 51 & \\
\hline Total bilirubin & & & 0.196 & & & 0.730 \\
\hline$\leq 17.1 \mathrm{umol} / \mathrm{L}$ & 61 & 82 & & 48 & 46 & \\
\hline$>17.1 \mathrm{umol} / \mathrm{L}$ & 30 & 58 & & 25 & 27 & \\
\hline AFP level & & & 0.026 & & & 0.861 \\
\hline$\leq 400 \mathrm{ng} / \mathrm{mL}$ & 64 & 78 & & 48 & 49 & \\
\hline$>400 \mathrm{ng} / \mathrm{mL}$ & 27 & 62 & & 25 & 24 & \\
\hline Tumor distribution & & & 0.299 & & & 0.385 \\
\hline Unilobar & 62 & 86 & & 45 & 50 & \\
\hline Bilobar & 29 & 54 & & 28 & 23 & \\
\hline Size of the largest tumor & & & $<0.001$ & & & 0.068 \\
\hline$\leq 50 \mathrm{~mm}$ & 33 & 16 & & 26 & 16 & \\
\hline$>50 \mathrm{~mm}$ & 58 & 124 & & 47 & 57 & \\
\hline Number of tumors & & & 0.224 & & & 0.320 \\
\hline Single & 40 & 73 & & 31 & 37 & \\
\hline Multiple & 51 & 67 & & 42 & 36 & \\
\hline
\end{tabular}

Abbreviations: PSM, propensity score matching; SD, standard deviation; IQR, interquartile range; AFP, alpha fetoprotein; INR, international normalized ratio.

\section{Discussion}

Compared to the combination therapy of TACE and MWA, treatment with TACE alone was an independent risk factor for poor PFS ( $\mathrm{P}=0.011$, hazard ratio: $2.751,95 \%$ CI: 1.678-4.510) and $\mathrm{OS}(\mathrm{P}<0.001$, hazard ratio: 1.614, 95\% CI: 1.116-2.332) in HCC patients beyond MC. According to the BCLC staging system, patients with $\mathrm{HCC}$ beyond $\mathrm{MC}$, in the absence of vascular invasion and extrahepatic spread, are classified into BCLC-A (single tumor greater than $5 \mathrm{~cm}$ ) or BCLC-B (more than three tumors). TACE is recommended in this class when curative treatment is not feasible. ${ }^{20-22}$ However, the treatment efficacy of TACE alone is dissatisfactory as it is difficult to achieve complete tumor necrosis after the procedure. ${ }^{23}$ Thermal ablation is widely used as a curative treatment for small HCC tumors, but the treatment efficacy of thermal ablation alone is also 

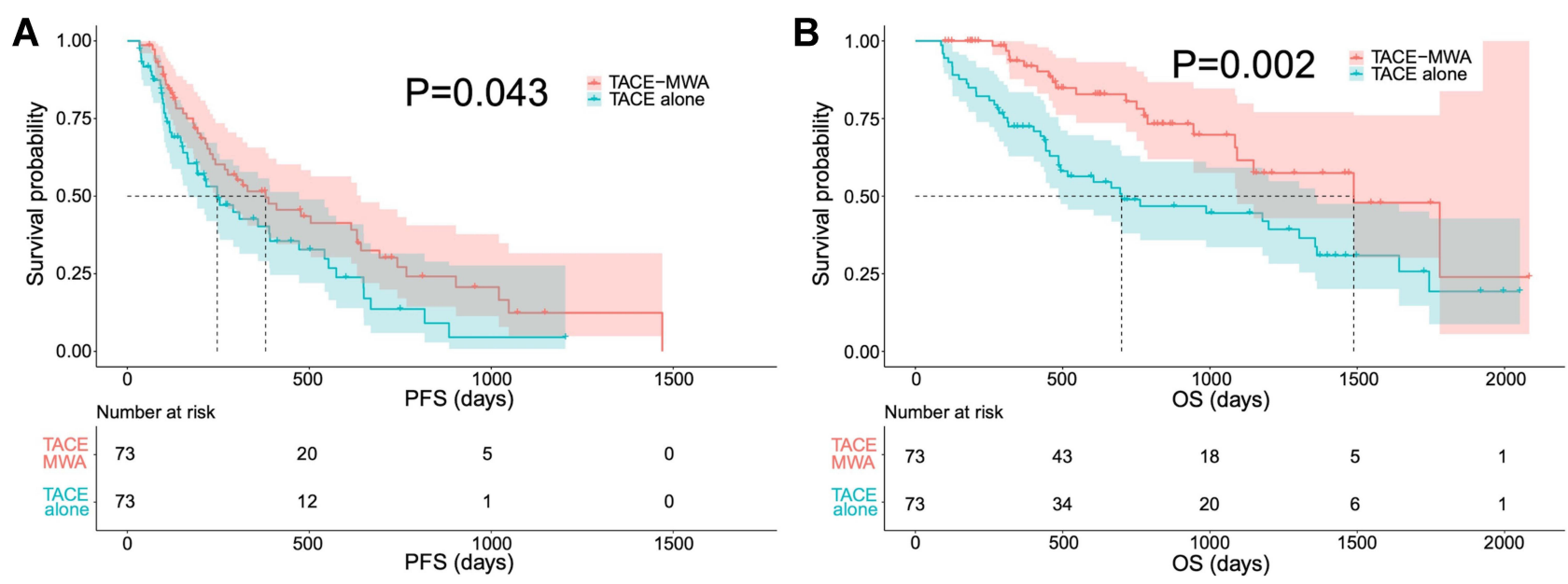

Figure 3 The comparison of PFS $(\mathbf{A})$ and OS $(\mathbf{B})$ after PSM. Both the PFS $(\mathrm{P}=0.043)$ and the OS $(\mathrm{P}=0.002)$ are significantly higher in patients treated with TACE-MWA than those of TACE alone.

dissatisfactory due to the high tumor burden of patients with HCC beyond MC. Bertrand et al demonstrated that the outcome of thermal ablation is only favorable in tumors smaller than $3 \mathrm{~cm} .{ }^{24}$ Leung et al reported that the initial tumor size is a significant prognostic factor for the local recurrence of liver malignancies treated with MWA. ${ }^{25}$ Recent evidence has suggested that the combination of TACE and thermal ablation has a synergistic effect on tumors, which may improve local tumor control for HCC patients, and the results of the present study support this finding. In the present study, greater PFS (380 days vs 247 days, $\mathrm{P}=0.043)$ and $\mathrm{OS}$ (1488 days vs 700 days, $\mathrm{P}=0.002$ ) benefits were noted in the TACE-MWA group compared to the TACE alone group after a one-to-one PSM analysis. The likely mechanisms underlying this benefit of the combination therapy are as follows: (a) MWA can result in more thorough tumor necrosis than TACE, which may improve the PFS rate, thus alleviating the tumor burden and improving the OS rate; (b) TACE may reduce the blood flow of the tumor and minimize the heat loss during thermal ablation, thus enlarging the ablative zone; (c) TACE is also effective in treating undetected satellite lesions adjacent to the main large tumor when a sufficient thermal ablative zone is not achieved; and (d) MWA can effectively destroy some hypovascular HCC tumors that do not respond well to TACE treatment alone. $^{26-29}$

Another important finding of the study was that TACE following MWA may improve the downstaging rate significantly more than TACE alone. Liver transplantation is considered the standard therapy for HCC patients within MC, with a low recurrence rate (10\%) and high 5 -year survival rates $(70 \%) .{ }^{30}$ However, for patients beyond MC, liver transplantation is controversial due to the relatively high post-treatment recurrence rate and shortage of liver grafts. ${ }^{31}$ Therefore, in HCC patients beyond $\mathrm{MC}$, a downstaging strategy is required. In principle, downstaging can be used to select patients with HCC who are initially beyond transplant criteria but will likely benefit from a liver transplant. ${ }^{32}$ Previous studies have reported similar effectiveness of liver transplant in patients who are initially beyond $\mathrm{MC}$ and later successfully downstage to within MC and HCC patients who meet the MC from the outset. ${ }^{33,34}$ Several locoregional therapies have been adopted to downstage HCC patients, and various downstage rates have been reported, ranging from $11.0 \%$ to $77.0 \%$ (29). In previous studies, TACE has been reported as the most popular treatment option for downstaging. ${ }^{33-35}$ However, not all HCC patients respond well to TACE since its efficacy depends on the target tumor having a good blood supply and adequate embolization of all tumor feeders. ${ }^{36}$ In the present study, the successful downstaging rate reported in patients treated with TACE alone was only $53.8 \%$; that is, nearly half of the HCC patients could not successfully downstage to receive liver transplantation. Although evidence showing the superiority of one downstaging modality over another is inadequate, the present study indicates that the combination therapy of TACE and MWA may result in a more successful downstaging rate than TACE alone $(77.1 \%$ vs $53.8 \%$, $\mathrm{P}=0.039$ ). 

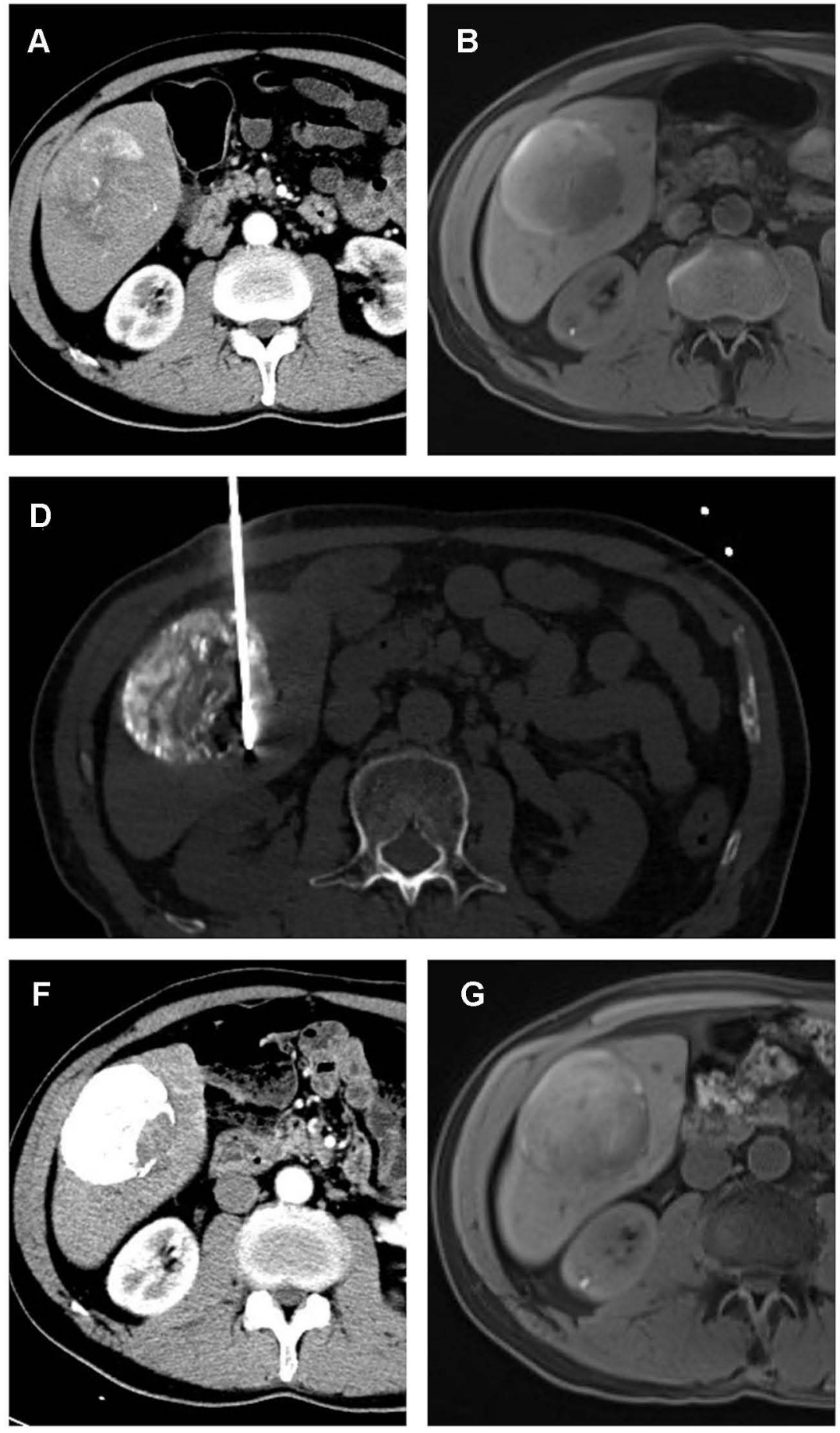
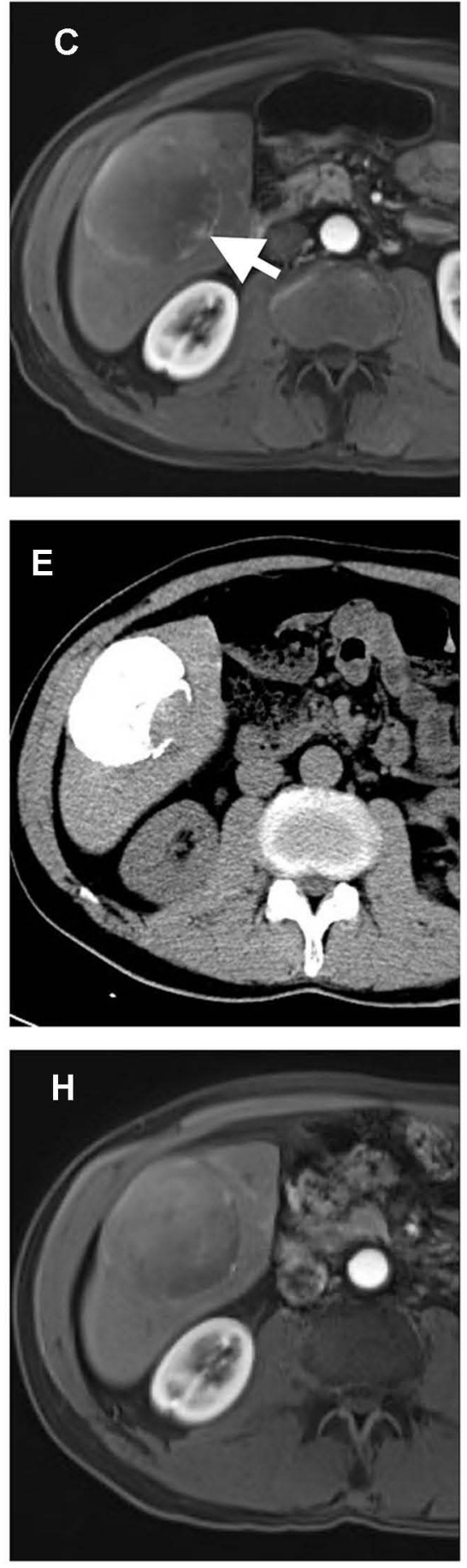

Figure 4 A 65-year-old male with a solitary HCC lesion in the right lobe of the liver. The lesion is 75 mm in size, and TACE is performed (A). After TACE, the MR imaging shows residual enhancement in the edge of the tumor (white arrow) (B and $\mathbf{C}$ ). A percutaneous MWA is performed in the residual enhancement area (D). After one month of ablation, no residual tumor is detected (E and $\mathbf{F})$. Four months after ablation, the patient is still within the Milan $\mathbf{C r i t e r i a}(\mathbf{G}$ and $\mathbf{H})$, which indicates a successful downstaging case.

There are several limitations to this study. First, this was a retrospective study with a small sample size. Therefore, selection bias may have influenced the results, and a further prospective study with a relatively large sample size should be conducted to confirm the findings. Second, the survival benefit of the liver transplant after successful downstaging in patients treated with TACE-MWA or TACE alone was not 

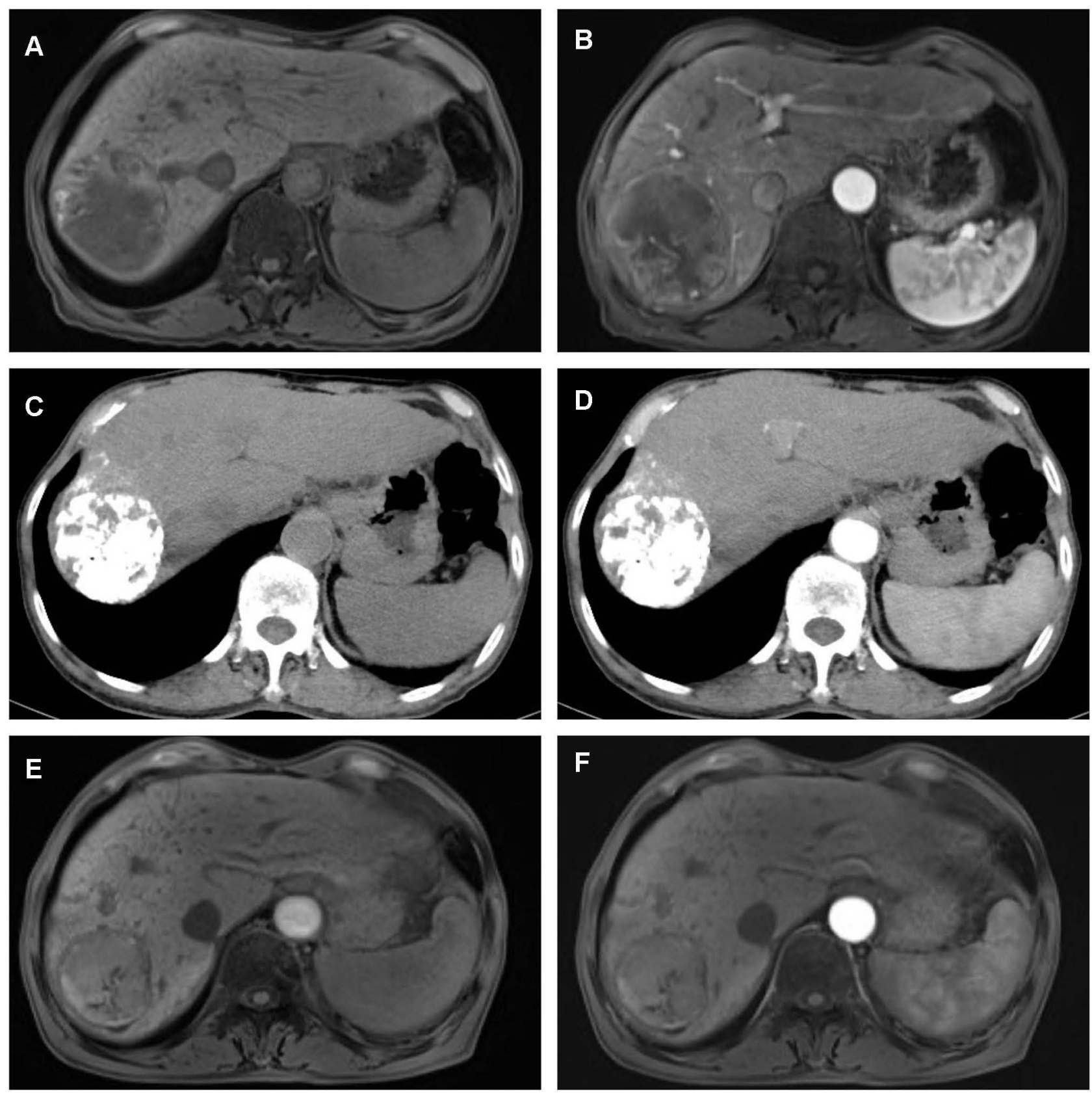

Figure 5 A 75-year-old male with a solitary HCC lesion in the right lobe of the liver. The lesion is 7 I mm in size (A and B), and TACE is performed. One month after TACE, there is no residual tumor detected on contrast-enhanced $C T(\mathbf{C}$ and $\mathbf{D})$ ). Five months after TACE, there is no recurrence found (E and $\mathbf{F})$, which indicates a successful downstaging case.

evaluated, as no patient received a liver transplant in the present study cohort. A further study should be conducted to confirm the survival benefit of a liver transplant after successful downstaging using TACE-MWA or TACE alone.

\section{Conclusion}

In conclusion, TACE-MWA may offer a survival benefit in terms of OS and PFS in HCC patients beyond the
MC compared to TACE alone. In addition, TACE-MWA may provide a significantly higher probability of downstaging within the MC than TACE alone, thereby increasing the chances of $\mathrm{HCC}$ patients receiving a liver transplant.

\section{Acknowledgment}

This project was supported by the National Natural Science Foundation of China (grant no. 81801813). 


\section{Disclosure}

The authors report no conflicts of interest in this work.

\section{References}

1. Llovet JM, Kelley RK, Villanueva A, et al. Hepatocellular carcinoma. Nat Rev Dis Primers. 2021;7:6.

2. European Assoc Study Liver. EASL clinical practice guidelines: management of hepatocellular carcinoma. $J$ Hepatol. 2018;69:182-236.

3. Amorim J, Franca M, Perez-Girbes A, Torregrosa A, Marti-Bonmati L. Critical review of HCC imaging in the multidisciplinary setting: treatment allocation and evaluation of response. Abdom Radiol. 2020;45:3119-3128.

4. Kwee SA, Wong LL, Sato MM, et al. Transarterial radioembolization for hepatocellular carcinoma with major vascular updates invasion: a nationwide propensity score-matched analysis with target trial emulation. J Vasc Interv Radiol. 2021;32:1258-1266.

5. Rivera K, Jeyarajah DR, Washington K. Hepatectomy, RFA, and other liver directed therapies for treatment of breast cancer liver metastasis: a systematic review. Front Oncol. 2021;11:643383.

6. De la Garza-ramos C, Overfield CJ, Montazeri SA, et al. Biochemical safety of ablative yttrium-90 radioembolization for hepatocellular carcinoma as a function of percent liver treated. $J$ Hepatocell Carcino. 2021;8:861-870.

7. Nisiewicz MJ, Kapoor H, Fowler KJ, Furlan A, Dugan AJ, Owen JW. Improved survival following transarterial radioembolization of infiltrative-appearance hepatocellular carcinoma. Abdom Radiol. 2021;46:1958-1966.

8. Frantz S, Matsuoka L, Vaheesan K, et al. Multicenter evaluation of survival and toxicities of hepatocellular carcinoma following radioembolization: analysis of the RESiN registry. $J$ Vasc Interv Radiol. 2021;32:845-852.

9. Mazzaferro V, Regalia E, Doci R, et al. Liver transplantation for the treatment of small hepatocellular carcinomas in patients with cirrhosis. New Engl J Med. 1996;334:693-699.

10. Lee WH, Byun HK, Choi JS, et al. Liver-directed combined radiotherapy as a bridge to curative surgery in locally advanced hepatocellular carcinoma beyond the Milan criteria. Radiother Oncol. 2020;152:1-7.

11. Famularo S, Di Sandro S, Giani A, et al. Treatment of hepatocellular carcinoma beyond the Milan criteria. A weighted comparative study of surgical resection versus chemoembolization. HPB. 2020;22:1349-1358.

12. Park C, Chu HH, Kim JH, et al. Clinical significance of the initial and best responses after chemoembolization in the treatment of intermediate-stage hepatocellular carcinoma with preserved liver function. J Vasc Interv Radiol. 2020;31:1998-2006.

13. Sun T, Ren YQ, Kan XF, et al. Advanced hepatocellular carcinoma with hepatic arterioportal shunts: combination treatment of transarterial chemoembolization with apatinib. Front Mol Biosci. 2020;7:607520.

14. Yang Y, Chen Y, Ye F, et al. Late recurrence of hepatocellular carcinoma after radiofrequency ablation: a multicenter study of risk factors, patterns, and survival. Eur Radiol. 2021;31:3053-3064.

15. Maas M, Beets-Tan R, Gaubert JY, et al. Follow-up after radiological intervention in oncology: ECIO-ESOI evidence and consensus-based recommendations for clinical practice. Insights Imaging. 2020;11:83.

16. Zheng L, Li HL, Guo CY, Luo SX. Comparison of the efficacy and prognostic factors of transarterial chemoembolization plus microwave ablation versus transarterial chemoembolization alone in patients with a large solitary or multinodular Hepatocellular carcinomas. Korean J Radiol. 2018;19:237-246.

17. Long J, Wang HG, Zhao P, et al. Transarterial chemoembolization combined with radiofrequency ablation for solitary large hepatocellular carcinoma ranging from 5 to $7 \mathrm{~cm}$ : an 8-year prospective study. Abdom Radiol. 2020;45:2736-2747.
18. Takuma Y, Takabatake H, Morimoto Y, et al. Comparison of combined transcatheter arterial chemoembolization and radiofrequency ablation with surgical resection by using propensity score matching in patients with hepatocellular carcinoma within Milan criteria. Radiology. 2013;269:927-937.

19. Yao FY, Kerlan RK, Hirose R, et al. Excellent outcome following down-staging of hepatocellular carcinoma prior to liver transplantation: an intention-to-treat analysis. Hepatology. 2008;48:819-827.

20. Yang J, Yang JY, Yan LN, Wen TF, Li B, Wang WT. Hepatic resection vs. transarterial chemoembolization for hepatocellular carcinoma beyond the Milan criteria with portal hypertension. Digest Liver Dis. 2018;50:713-719.

21. Sangiovanni A, Colombo M. Treatment of hepatocellular carcinoma: beyond international guidelines. Liver Int. 2016;36:124-129.

22. Heinzow HS, Brockmann JG, Kohler M, et al. Liver transplantation versus supraselective transarterial chemoembolization in palliative patients with hepatocellular carcinoma exceeding the Milan Criteria - is it time for a more individual approach? Ann Transpl. 2013;18:515-524.

23. Burgio MD, Sartoris R, Libotean C, et al. Lipiodol retention pattern after TACE for HCC is a predictor for local progression in lesions with complete response. Cancer Imaging. 2019;19:75.

24. Bertrand J, Caillol F, Borentain P, et al. Percutaneous hepatic radiofrequency for hepatocellular carcinoma: results and outcome of 46 patients. Hepat Med. 2015;7:21-27.

25. Leung U, Kuk D, D'Angelica MI, et al. Long-term outcomes following microwave ablation for liver malignancies. $\mathrm{Br} \quad J$ Surg. 2015;102:85-91.

26. Zaitoun MMA, Elsayed SB, Zaitoun NA, et al. Combined therapy with conventional trans-arterial chemoembolization (cTACE) and microwave ablation (MWA) for hepatocellular carcinoma $>3-<5$ cm. Int $J$ Hyperther. 2021;38:248-256.

27. Gui CH, Baey S, D'cruz RT, Shelat VG. Trans-arterial chemoembolization plus radiofrequency ablation versus surgical resection in hepatocellular carcinoma - a meta-analysis. EJSO. 2020;46:763-771.

28. Zhao JN, Wu JX, He MY, et al. Comparison of transcatheter arterial chemoembolization combined with radiofrequency ablation or microwave ablation for the treatment of unresectable hepatocellular carcinoma: A systemic review and meta-analysis. Int $J$ Hyperther. 2020;37:624-633.

29. Ni JY, Fang ZT, Sun HL, et al. A nomogram to predict survival of patients with intermediate-stage hepatocellular carcinoma after transarterial chemoembolization combined with microwave ablation. Eur Radiol. 2020;30:2377-2390.

30. Marrero JA, Kulik LM, Sirlin CB, et al. Diagnosis, staging, and management of hepatocellular carcinoma: 2018 practice guidance by the American association for the study of liver diseases. Hepatology. 2018;68:723-750.

31. Chiao H, Yang CHE, Frenette CT. Review on liver transplant for hepatocellular carcinoma. Transl Cancer Res. 2013;2:472-481.

32. Bova V, Miraglia R, Maruzzelli L, Vizzini GB, Luca A. Predictive factors of downstaging of hepatocellular carcinoma beyond the Milan criteria treated with intra-arterial therapies. Cardiovasc Inter Rad. 2013;36:433-439.

33. Shi F, Lian SS, Mai QC, et al. Microwave ablation after downstaging of hepatocellular carcinoma: outcome was similar to tumor within Milan criteria. Eur Radiol. 2020;30:2454-2462.

34. Rudnick SR, Russo MW. Liver transplantation beyond or downstaging within the Milan criteria for hepatocellular carcinoma. Expert Rev Gastroent. 2018;12:265-275.

35. Kim Y, Stahl CC, Makramalla A, et al. Downstaging therapy followed by liver transplantation for hepatocellular carcinoma beyond Milan criteria. Surgery. 2017;162:1250-1258.

36. Arizumi T, Minami T, Chishina H, et al. Time to transcatheter arterial chemoembolization refractoriness in patients with hepatocellular carcinoma in kinki criteria stages b1 and b2. Dig Dis. 2017;35:589-597. 


\section{Publish your work in this journal}

The Journal of Hepatocellular Carcinoma is an international, peerreviewed, open access journal that offers a platform for the dissemination and study of clinical, translational and basic research findings in this rapidly developing field. Development in areas including, but not limited to, epidemiology, vaccination, hepatitis therapy, pathology and molecular tumor classification and prognostication are all considered for publication. The manuscript management system is completely online and includes a very quick and fair peer-review system, which is all easy to use. Visit http://www.dovepress.com/ testimonials.php to read real quotes from published authors.

Submit your manuscript here: https://www.dovepress.com/journal-of-hepatocellular-carcinoma-journal 